\title{
Entrevista com Bertrand Daunay e Daniel Bart:* Pode-se levar a sério o PISA?
}

\author{
Adilson Ribeiro de Oliveira**
}

Como se sabe, o Programa Internacional de Avaliação de Estudantes (PISA - do inglês Programme for International Student Assessment) é um empreendimento conduzido pela Organização para Cooperação e Desenvolvimento Econômico (OCDE). Trata-se de uma avaliação comparada, aplicada a estudantes na faixa etária dos 15 anos, idade em que se estima o término da escolaridade básica obrigatória na maioria dos países que participam da avaliação, o que, no Brasil, corresponde ao final do Ensino Fundamental.

De acordo com o Instituto Nacional de Estudos e Pesquisas Educacionais Anísio Teixeira (INEP), órgão responsável pela realização do PISA no Brasil, o objetivo desse programa é produzir indicadores sobre a qualidade da educação oferecida nos países participantes, de modo a promover discussões que subsidiem políticas de melhoria da educação básica. As avaliações acontecem a cada três anos, abrangendo três áreas do conhecimento - Letramento em Leitura, Cultura Matemática e Cultura Científica - , sendo que a cada ano uma dessas três áreas é enfatizada. Segundo a OCDE, não se trata somente de avaliar o que os alunos sabem em leitura, matemática e ciências, mas também de compreender o que eles são capazes de fazer com esses conhecimentos. ${ }^{1}$ Além de diagnosticar competências dos estudantes, o PISA ainda procura coletar informações que possam relacionar o desempenho dos estudantes a variáveis demográficas, socioeconômicas e educacionais, de modo que tais informações possam ser utilizadas pelos poderes públicos como um instrumento na idealização, planejamento, implementação e refinamento de políticas educativas.

No ano de 2018, a área de conhecimento enfatizada foi a Leitura: momento oportuno para esta entrevista com os professores e pesquisadores Bertrand Daunay e Daniel Bart, especialistas franceses que publicaram (para além de vários artigos sobre o tema nos últimos anos) em 2016, pelas edições Croquant, na França, a obra Les blagues à PISA: le discours sur l'école d'une institution internacionale e, em 2018, pela editora Mercado de Letras, para satisfação dos leitores brasileiros interessados na temática, Pode-se levar a sério o PISA? O tratamento do texto literário em uma avaliação internacional, convite a uma análise crítica e, em consequência, a uma reflexão engajada em melhor compreensão de uma faceta dessa avaliação de impacto global.

Daniel Bart é professor na área de Ciências da Educação na Universidade de Lille e membro da equipe de pesquisa didática Théodile-CIREL. ${ }^{2}$ Seus trabalhos de pesquisa visam a analisar as práticas de avaliação (institucionais e profissionais) do mundo escolar e universitário, particularmente no

\footnotetext{
* Entrevista realizada em Lille, França, em abril de 2018, por ocasião do estágio pós-doutoral do professor Adilson Ribeiro de Oliveira na Universidade de Lille, sob a supervisão de Bertrand Daunay e Daniel Bart. Versão traduzida do francês pelo entrevistador, com revisão dos entrevistados, a quem se dirigem sinceros agradecimentos.

** Professor do Instituto Federal Minas Gerais (IFMG - Campus Ouro Branco).

1 Daí a explicação para a opção pela noção de letramento em leitura (do inglês reading literacy) ao invés de compreensão em leitura, por exemplo.

2 Théodile (Teoria Didática Leitura Escrita) é uma das equipes de pesquisa do laboratório Centro Interuniversitário de Pesquisa em Educação de Lille (CIREL) da Universidade de Lille.
} 
campo da escrita acadêmica, apoiando-se particularmente nos avanços da pesquisa em didática sobre avaliação. Nos últimos anos, ele vem se interessando, juntamente com Bertrand Daunay, pela temática da avaliação no teste internacional do PISA (com foco na questão da escrita e do texto literário) e pelos modos como a escrita de pesquisa é tomada nesse Programa.

Bertrand Daunay, ex-professor de francês no ensino secundário e formador de professores, atualmente é professor na área de Ciências da Educação na Universidade de Lille. Especialista em Didática do Francês, especificamente no campo da literatura, atualmente desenvolve pesquisas em Didática Comparativa, o que o leva a questionar particularmente os fundamentos epistemológicos e metodológicos das Didáticas. ${ }^{3}$ Ex-diretor do Théodile-CIREL, é presidente honorário da Associação Internacional de Pesquisa em Didática Francesa (AIRDF). Seus últimos trabalhos, conduzidos em colaboração com Daniel Bart, propõem uma discussão teórica do PISA, particularmente quanto ao teste de letramento em leitura.

Adentremos, então, esse instigante e intrigante universo que é o PISA e seus múltiplos desafios sob o olhar atento desses dois grandes pesquisadores que nos honram com esta entrevista.

Recebido: 12/02/2019

Aceito: 16/07/2019

$3 \mathrm{Na}$ França, a Didática é conduzida de forma especializada em cada domínio de conhecimento, o que explica o plural Didáticas. 
Adilson Ribeiro de Oliveira: Vocês publicaram, no Brasil, em 2018, o livro Pode-se levar a sério o PISA? O tratamento do texto literário em uma avaliação internacional. Falem-nos um pouco sobre essa obra: sua abordagem, seus objetivos, suas conclusões.

Daniel Bart: Como o subtítulo do livro indica, essa publicação pretende questionar de forma crítica, até mesmo polêmica, o tratamento que uma avaliação internacional de prestígio, como o PISA, reserva ao texto literário e à literatura. Desejamos falar não só da maneira como o Programa utiliza obras literárias como suporte para seus testes, mas também de como ele aborda a literatura de um ponto de vista mais "teórico", quando se compromete, por exemplo, a descrever tipos de textos ou situações de leitura ou quando trata da "qualidade literária" ou da metalinguagem literária. Em um campo como a literatura, que tem uma longa e complexa história teórica, é realmente surpreendente observar o quanto os relatórios do PISA publicados pela OCDE e os extratos de testes tornados públicos multiplicam as aproximações, os clichês e as banalidades para tratar essas questões, que o tom sentencioso e peremptório característico do discurso do Programa não esconde.

Bertrand Daunay: Com efeito, é essa lacuna entre a inclinação do PISA à altivez e o conteúdo real bastante pobre de seus escritos que tentamos mostrar nesse pequeno livro, analisando particularmente o conjunto de exercícios tornados públicos pelo PISA cujo objeto é a compreensão de um texto literário. Procuramos mostrar que grande parte de seu discurso tem o nível de seriedade de uma conversação social banal sobre as práticas de leitura dos alunos, seu nível de compreensão, o ensino da abordagem dos textos ou a literatura de forma global. Para quem conhece o desenvolvimento, desde a década de 1950, dos estudos literários no mundo (e particularmente os da França, bem conhecidos no Brasil), essa mistura de arrogância e inconsistência teórica é surpreendente. Dito isso, ao nos concentrarmos no tratamento do texto literário no PISA, estamos apenas escolhendo um ângulo de abordagem específico, mas significativo: nós queremos de fato descrever mais amplamente o funcionamento do discurso do PISA e, assim, a extensão das falhas no Programa, que ele se esforça para negar, diríamos mesmo enterrar.

Daniel Bart: $\mathrm{Na}$ mesma linha de Blagues à PISA, nosso livro anterior publicado na França, nós nos posicionamos em uma lógica de descrição e crítica do discurso do PISA como um todo. É esse o significado do título do nosso último livro, cuja pergunta é apenas retórica: pode-se levar a sério o PISA? A literatura é uma ferramenta, para nós, destinada a entrar profundamente no discurso desse Programa (em vez de tratá-lo na sua superfície).

Adilson Ribeiro de Oliveira: A abordagem do livro versa especificamente sobre o texto literário no teste de letramento em leitura do PISA. Vocês diriam que os textos não literários utilizados nos testes do Programa também merecem uma análise discursiva de mesma natureza? Poderiam falar um pouco sobre essa questão?

Bertrand Daunay: Nós estávamos particularmente interessados no tratamento do texto literário no PISA, seguindo outros estudos como os de Isabelle Robin (2002), que também havia trabalhado no quadro do PISA: em sua análise de uma unidade, "O presente", ${ }_{4}$ ela mostrou os limites do tratamento literal de

4 A expressão "unidade" refere-se a um item de avaliação do PISA que corresponde a um conjunto formado por texto, pequena apresentação desse texto e questões discursivas e de múltipla escolha. O título da unidade é o título do texto utilizado como suporte na composição da unidade. 
textos literários no PISA. Mas, de fato, os textos literários representam apenas parte dos textos utilizados pelo Programa para construir seus testes de letramento em leitura. E também existem trabalhos críticos muito interessantes sobre esses exercícios. Por exemplo, no início dos anos 2000, logo após o lançamento do PISA, o especialista em Didática do Francês Daniel Bain (2003) debruçou-se sobre uma unidade do PISA desse tipo, "O lago Chade", em que os alunos deveriam responder a questões sobre gráficos e figuras extraídos de um atlas arqueológico. Bain mostrou, de forma bastante convincente, as limitações da abordagem do PISA à leitura e à compreensão, bem como os obstáculos que essa abordagem poderia representar para o ensino. Do mesmo modo, Marc Romainville (2002) também já havia se perguntado sobre os limites da abordagem do PISA, questionando, em particular, um exercício para entender um diagrama representando a população ativa, extraído de um manual de economia do ensino secundário (unidade “Trabalho"). Assim, pode-se dizer, com efeito, que a análise das unidades construídas com textos que não sejam literários permite trabalhos muito interessantes e estimulantes, do nosso ponto de vista, e as nossas análises poderiam perfeitamente entrar em diálogo com eles.

Daniel Bart: Para além do letramento em leitura, além disso, poder-se-ia dizer o mesmo das unidades relativas aos outros domínios testados: há matéria para um livro inteiro sobre o tratamento das ciências ou da matemática, mesmo de "letramento financeiro", que é outra área (cada vez mais importante) da avaliação do PISA. De fato, a primeira parte do livro, assim como nossa obra precedente, avança em algumas proposições a esse respeito. Sem poder fazer referência aqui aos muitos trabalhos que analisaram unidades desses domínios, como o de Svein Sjøberg (2015) para unidades de ciências, digamos que mostramos, de nossa parte, o quanto a análise discursiva que fazemos pode contribuir, em termos de uma melhor compreensão do funcionamento do PISA em geral. É assim que nós mostramos o caráter parcialmente absurdo de algumas "figuras" do PISA, como o carpinteiro, o agricultor, a estudante de Cingapura Mei-Ling e assim por diante - para nos referir a personagens que figuram em textos utilizados nos testes de letramento em leitura do PISA cujas abordagens são postas em discussão em Pode-se levar a sério o PISA?..

Adilson Ribeiro de Oliveira: Vocês acabam de explicitar algumas questões importantes quanto ao tratamento de textos em geral nos testes do PISA. Afinal, qual é a concepção de leitura que o PISA propõe usar no teste de letramento em leitura? Na opinião de vocês, trata-se de uma noção que vai ao encontro das abordagens mais recentes sobre leitura? E mais: pode-se dizer que essa concepção de leitura é de fato contemplada no teste?

Bertrand Daunay: Podemos dizer que o PISA parece dar à leitura e à compreensão em leitura uma concepção mais ampla, apoiada na noção de letramento. Nos documentos de apresentação do PISA 2015, por exemplo, encontramos esta definição de compreensão: "Compreender não é apenas entender e usar textos escritos, mas também pensar sobre eles e neles se engajar. Essa capacidade deve permitir a cada um atingir seus objetivos, desenvolver seu conhecimento e potencial e participar ativamente da sociedade." (OCDE, 2013, p. 13). ${ }^{5}$ O que é interessante observar é que, apesar dessa definição ampla de compreensão, aparentemente inserida no

5 A definição já foi apresentada de forma idêntica (mas sem a expressão "e neles se engajar") no documento introdutório do primeiro ciclo do PISA. (OCDE, 1999, Mesurer les compétences et connaissances des élèves. Un nouveau cadre d'évaluation. Paris: Éditions OCDE., p. 24). (Tradução nossa) 
funcionamento e na dinâmica social e cultural, a estrutura "teórica" do PISA e seus testes parecem atuar na direção de uma naturalização da leitura. Nós apresentamos muitos exemplos, em nosso livro, que mostram que essa concepção, tal como se desdobra nos testes (pelo menos naqueles que são acessíveis), é um reducionismo psicológico, que não só considera que o sentido de um texto reside nele mesmo e depende das intenções do seu "autor" (noção que resta não problematizada), mas ainda que pode ser apreendido identicamente por um sujeito "leitor", em um processo comunicacional sem embate. Uma concepção como essa pode estar de acordo com estudos recentes em psicologia cognitiva (cujo reducionismo metodológico é justificado pelas restrições de investigações específicas), mas ignora outras pesquisas, como as abordagens socioantropológicas de "práticas", por exemplo, ou os trabalhos como os seus, que tentam compreender o papel das representaçoes sociais na produçao de sentido na leitura (OLIVEIRA, 2017); no entanto, todas essas pesquisas não seriam sem interesse se queremos abordar o letramento não apenas sob uma estrita perspectiva das habilidades individuais, mas sob uma visão mais ampla das questões sociais que o determinam (em termos de discurso, representações, instituições, poderes, etc.).

Daniel Bart: Tomemos uma consequência caricatural de tal naturalização da leitura na concepção do PISA: enquanto a definição que ele dá de compreensão (que acabamos de recordar) insiste na ideia de usar textos escritos, constatamos, com surpresa, na tipologia das situações de leitura proposta pelo PISA - leituras para uso público, leituras profissionais, etc. que essas "situações" não remetem a situações de uso real da leitura, mas a usos e contextos para os textos em questão supostamente pretendidos por seus autores. Mas, de forma mais geral, é notável constatar que não há diálogos nos escritos do PISA com trabalhos críticos que possam discutir a relevância das escolhas teóricas do Programa sobre a leitura e, mais amplamente, sobre a ideia de habilidades genéricas, como o trabalho de Goody (2001), por exemplo. É o que podemos observar no Capítulo 2 do livro, no qual afirmamos que a estrutura conceitual para avaliar o letramento em leitura na edição de 2009 do PISA é fortemente amparada em referências teóricas psicológicas e cognitivas anglo-saxônicas sem que se aponte o fato de que se trata de uma escolha teórica entre outras abordagens possíveis e tampouco que se apresentem as razões para essa escolha. Como lembra Jean-Paul Bronckart no prefácio do livro, o PISA trata notavelmente a questão da leitura e do letramento em leitura como "fatos estabelecidos", sem pôr à mostra os debates científicos e mesmo as controvérsias que essas temáticas geraram e ainda geram.

Adilson Ribeiro de Oliveira: Quais são as motivações que os levaram a debruçar-se sobre o PISA, sua organização, seus discursos e contradições? Quais os aportes teóricometodológicos em que vocês se apoiam nessa empreitada?

Bertrand Daunay: Essa dinâmica de trabalho colaborativo sobre o PISA entre nós dois já dura vários anos. E é sempre um pouco ilusório querer reconstruir a posteriori as motivações ou os interesses que estão na origem de tal dinâmica. Nossas respectivas especialidades, as avaliações, da parte de Daniel Bart, e a didática da literatura, da minha parte, evidentemente, muito motivaram esse interesse comum em avaliar o letramento no PISA, mas, para além disso, é provável que nossa curiosidade por esse Programa seja nutrida pelo nosso interesse comum em abordagens teóricas críticas que põem em debate discursos convencionados sobre a escola, especialmente 
aqueles que se pautam em autoridade institucional. Um programa dessa amplitude, que se apresenta como uma referência mundial em matéria de avaliação, que não hesita em aconselhar países do mundo inteiro sobre boas práticas pedagógicas por meio de uma abundante produção discursiva cheia de incongruências, foi para nós um campo — tanto de jogo quanto de pesquisa - por demais extraordinário! Não somos os únicos, é claro, a ter investido no terreno de críticas ao PISA (embora se deva precisar que mais numerosos são os pesquisadores que se abstêm de criticar esse Programa). Mas nosso percurso tem algo de específico, pois nossa abordagem global do discurso do PISA se nutre de uma análise minuciosa dos conteúdos mesmos de seus testes, o que caracteriza uma análise didática. Essa dupla abordagem, discursiva e didática, faz melhor emergir, parece-nos, os problemas dessa avaliação internacional.

Daniel Bart:Com relação às abordagens teóricas em que esses trabalhos se apoiam, além do que Bertrand acabou de dizer, podemos mencionar, de início, a tradição da pesquisa crítica em didática sobre as avaliações. Quer se pense nos escritos de Chevallard (1986), em Didática da Matemática, ou nos trabalhos de Dabène (1994), Halté (1984), Delcambre (1994) ou Nonnon (2005), em Didática do Francês, numerosos especialistas do campo procuraram questionar os limites dos dispositivos comuns de avaliação escolares ou institucionais, nas suas relações com os conteúdos disciplinares de ensino. Além disso, nós nos apoiamos em um rico fundo internacional de pesquisa sobre a metodologia do PISA. O sucesso desse Programa foi de fato acompanhado por muitos trabalhos críticos de especialistas como Goldstein (2017), Sjøberg (2016) ou Hopmann, Brinek e Retzl (2007), que analisam, cada um de acordo com suas respectivas abordagens, os limites dessa avaliação. Também nos beneficiamos de trabalhos empreendidos no Brasil e podemos citar, como exemplar, o notável trabalho da revista brasileira Educação \& Sociedade (2016), que, em uma edição dedicada ao PISA, abordou a questão com seriedade e de maneira. Finalmente, podemos também destacar que nos inspiramos em uma certa tradição francesa de análise do discurso, que visa, em particular, a descrever um funcionamento discursivo específico em relação à posição (política, institucional, científica, etc.) que ocupa o produtor desse discurso. Mesmo se nos inspiramos de maneira bem distante dessa corrente de pesquisa da Análise do Discurso, podemos dizer que ela irriga nossa abordagem.

Bertrand Daunay: Como diz Daniel, nosso empréstimo à Análise da Discurso é difusa. De fato, não temos uma abordagem sistemática, que poderia ter-nos conduzido, por exemplo, à determinação de um "arquivo" e de uma "formação discursiva", para usar as palavras de Michel Foucault (2005), em A arqueologia do saber, a quem uma certa tradição da Análise do Discurso Francesa deve muito. Mas, no quadro do corpus específico do PISA, implementamos os princípios dessa abordagem, ${ }^{6}$ e é o que nos permite mostrar notadamente que o discurso do PISA é o de uma instância que engloba e ultrapassa o conjunto de autores efetivos dos textos do Programa, o que, às vezes, leva, nós mostramos, a uma forma de discurso quase automático. Duas grandes características da análise do discurso permitiramnos chegar a essa demonstração: por um lado, a identificação das modalidades do discurso, o que a Análise do Discurso, tomando de empréstimo da Retórica, chama de o ethos do escritor (a imagem que emerge de seu discurso); identificamos um ethos de certeza e de altivez (que dá lugar a culpabilizações e admoestações diversas); é esse ethos que permite escrever disparates muito tranquilamente... A outra grande característica

6 Como fizeram também, a propósito do letramento científico, Teixeira, Nardi e Lima (2017). 
é a identificação das recorrências do discurso, que permitem identificar seu núcleo duro e seus fundamentos ideológicos (por exemplo, a função do real, a autenticidade, o papel do indivíduo, etc.). A recorrência não segue necessariamente a repetição explícita de uma ideia: uma mesma ideia pode ser visível pelo fato de estar implícita e às vezes pelo fato de que existe um ambiente idêntico para certos propósitos; por exemplo, uma recorrência visível é o fato de que os resultados do PISA são frequentemente apresentados em um ambiente que pressupõe que é o indivíduo que está em causa, não o sistema econômico... Isso não é dito, mas quando resultados do PISA são acompanhados de observações sobre a vontade ou o esforço, entendemos em meias palavras; nós nos empenhamos em fazer sobressaírem esses implícitos.

\section{Adilson Ribeiro de Oliveira: Em Les blagues à}

PISA, vocês abordam, de forma complexa, mas bem-humorada, as contradições apresentadas no discurso da OCDE sobre os mecanismos que engendram a realização do PISA e seus resultados. Segundo esse discurso, os jovens estudantes devem tornar-se "cidadãos ativos, reflexivos e inteligentes". O que isso significa para o PISA? E para vocês?

Daniel Bart: Eis aí um bom exemplo do que a análise do discurso permite ver. Com efeito, o sentido dessas poucas palavras extraídas do PISA remete-nos, de maneira mais ampla, ao funcionamento do discurso desse Programa. Por meio dessa curta referência que você faz a "cidadãos ativos, reflexivos e inteligentes", pelos quais se interessa o PISA, vemos, de fato, desenvolverem-se todas as características de um discurso descontrolado, o qual não se esperaria em uma avaliação institucional dessa envergadura. Isso porque o PISA pretende de fato avaliar estudantes de 15 anos para verificar se o seu percurso escolar permitiu-lhes adquirir as competências que os conduziriam a tornaremse "cidadãos ativos, reflexivos e inteligentes". Podemos interrogar-nos sobre o exercício de predição ou mesmo da adivinhação que isso representa, mas, embora possamos nos interessar, como você acaba de nos convidar, pelo significado desses termos, deve-se admitir que, em momento algum, o PISA precisa o que pretende com essas categorias que ele mobiliza, no entanto, incessantemente. O que é uma pena, porque seria curioso saber mais especificamente quem seriam esses cidadãos não ativos, não reflexivos e não inteligentes...

Bertrand Daunay: Esse exemplo é tão surpreendente que nós o retomamos no livro publicado no Brasil, desenvolvendo-o por meio de uma referência ao linguista francês Oswald Ducrot (1984 [1987]), que interroga sobre a admissibilidade de um discurso dessa natureza em um texto científico. Mas o trabalho de categorização espontânea do PISA é considerável e povoa seus textos de novas categorias, não debatidas, mas fundadas no que Roland Barthes (1957 [2013]) chama de senso comum: o estudante de 15 anos, a democracia, a carpintaria, a realidade, a autenticidade, etc. À revelia de toda lógica científica, que deveria identificar os métodos de construção dessas categorias, ou pelo menos assinalar sua fragilidade conceitual, o PISA aposta na transparência da linguagem e na obviedade das coisas para se entregar à sua propensão ao que nós chamamos de “essencialização do real".

Adilson Ribeiro de Oliveira: A propósito, quais as aproximações e distanciamentos entre a obra publicada na França e a publicada no Brasil?

Bertrand Daunay: As pesquisas que desenvolvemos levaram-nos a examinar o funcionamento do discurso do PISA, e nossos 
dois livros perseguem o mesmo objetivo de analisar esse discurso, mas de duas maneiras diferentes. No livro publicado na França, Les blagues à PISA, trata-se mesmo de uma abordagem polêmica, num tom, como você disse, mais humorístico ou irônico, constituído pelo acúmulo de exemplos de "piadas", em que nos permitimos uma análise rápida, enquanto que o livro publicado no Brasil dirige-se mais ao detalhe de análise e, sendo também bastante crítico, preocupa-se mais com uma argumentação fundamentada teoricamente.

Daniel Bart: De fato, a Croquant, que publicou o livro Blagues à PISA, não é uma editora acadêmica, ao contrário da Mercado de Letras, editora de Pode-se levar a sério o PISA? O livro brasileiro, portanto, inscreve-se mais claramente nas modalidades correntes da escrita científica, o que se explica também pelo fato de que ele se funda em trabalhos publicados anteriormente em revistas ou obras científicas francesas. Outra diferença é que a concepção de um livro destinado a um público leitor brasileiro conduziu-nos, é claro, a retomar certas análises ou certos resultados para assentá-los em relação com o contexto brasileiro e com a recepção dos resultados do PISA no Brasil. Além disso, no livro brasileiro, analisamos principalmente as unidades fundadas em um texto literário, enquanto que, em Les blagues à PISA, destinamos uma grande parte das análises a unidades originárias do campo da matemática.

Adilson Ribeiro de Oliveira: De acordo com o INEP, "a OCDE está plenamente ciente das circunstâncias diferentes nos distintos países (são mais de 80 países participantes do PISA 2018). Não existe um modelo educacional com um 'padrão único para todos' os países. Não é possível ou adequado 'copiar e colar' o sistema educacional de um país para o outro." ${ }^{\text {77 }}$ Como e em que medida essa preocupação é levada a cabo de fato no PISA?

Daniel Bart: Aqui, também, a citação que você faz do INEP parece bastante interessante porque é, para nós, exemplar do funcionamento do discurso do PISA. Esse Programa pode muito bem, como aqui, por meio do INEP, proclamar que está plenamente ciente das diferenças entre os países participantes de sua avaliação e que não existe um modelo educacional padrão único para todos os países e, ao mesmo tempo, difundir relatórios que contenham pistas de ações públicas que supostamente contribuam para a melhoria do funcionamento escolar e sejam dirigidas de maneira muito geral a todos os países, sem verdadeiramente levar em conta sua história, suas especificidades organizacionais, culturais ou políticas. Mas isso não é muito surpreendente, uma vez que o objetivo da OCDE, que coordena o PISA, é promover certas orientações políticas e econômicas em escala mundial. ${ }^{8}$ E então o PISA nem sempre abraça a delicadeza política e histórica: como mostramos nolivro, esse Programa pode assim afirmar, a propósito da unidade "Democracia em Atenas", construída a partir de um excerto adaptado da Guerra do Peloponeso, de Tucídides, que é razoável pensar que a maioria dos alunos avaliados "são bastante familiarizados com a história como um conceito e têm uma noção - mesmo que não necessariamente estruturada — do que é a democracia”. (OCDE, 2012). Essa é uma afirmação ousada se pensarmos, por um lado, na semelhança entre a democracia da qual Tucídides fala e as formas de democracia hoje,

7 Cf. <http://download.inep.gov.br/acoes internacionais/ pisa/documentos/2016/pisa_brasil_2015_perguntas_e respostas.pdf $>$. Acesso em: 6 abr. 2018.

8 Nisso se pode ver um "viés ideológico" do PISA, como apresenta Alavarse (2016), em entrevista concedida à Carta Educação, "Pisa, um viés ideológico", 15 mar. 2016. Disponível em: <http://www.cartaeducacao.com.br/ entrevistas/pisa-um-vies-ideologico/ $>$. Acesso em: 6 jun. 2018. 
e, por outro lado, no fato de que vários países participantes do PISA, sem dúvida, nada têm a ver com democracia...

Bertrand Daunay: Em outro nível, encontramos esse estranho paradoxo do PISA em querer ao mesmo tempo levar em conta as diferenças entre os países que participam de sua avaliação e construir um teste fundado metodologicamente na neutralização de todas as diferenças linguísticas, culturais, curriculares, etc., entre esses países participantes para garantir as comparações. Esse é um paradoxo pelo qual nos interessamos particularmente, no livro, no capítulo 5, "Os limites de uma abordagem 'universalista' do real". Nesse capítulo, queremos mostrar como o PISA, que intenta avaliar os alunos o mais próximo das exigênicas da sua "vida real" e da diversidade de contextos culturais, linguísticos ou sociais, por meio da noção de letramento, na verdade constrói um teste que supõe resistir a qualquer particularidade - de tempo, de lugar, de contexto - , que tende, assim, a promover uma forma de realidade padronizada.

Adilson Ribeiro de Oliveira: Nesse quadro, na opinião de vocês, quais são os maiores problemas de uma avaliação educacional em larga escala e de caráter internacional como a que se propõe o PISA? Há, diferentemente, vantagens? Quais seriam?

Bertrand Daunay: Nossa posição não é a de negar as conveniências de qualquer avaliação internacional nem de negar que projetos importantes são implementados em alguns países para promover a educação das meninas ou dos alunos mais desfavorecidos e para desenvolver a formação de professores e seus formadores, etc. Uma das vantagens dessas comparações internacionais é, talvez, a de manter no debate público esses importantes desafios educacionais.
Resta saber se a abordagem adotada pelo PISA permite tratar politicamente essas questões fundamentais com a seriedade que elas merecem: várias centenas de especialistas assinaram uma petição, em 2014, solicitando, justamente, a suspensão do PISA, com base, em particular, não somente no fato de que, com o seu ritmo trienal de implementação, o Programa não se permite se ocupar de tais desafios que demandam medidas de longo prazo; mas também no fato de que a competição educacional internacional que o PISA promove pode conduzir a tomadas de medidas negativas para os sistemas educativos.

Daniel Bart: É difícil hierarquizar os limites que, como qualquer investigação científica, uma avaliação como a do PISA encontra. Mas o que talvez seja o mais questionador é justamente a maneira pela qual todo o funcionamento do PISA tende a apresentar suas escolhas conceituais e metodológicas, necessárias e inerentes a qualquer empreendimento de pesquisa, como naturais, evidentes e não inscritas em quadros de discussões argumentadas e contraditórias do diálogo de pesquisa habitual. Como mostramos no Capítulo 2 de Pode-se levar a sério o PISA?, "O discurso do PISA: uma exposição em forma de imposição", uma das peculiaridades dos escritos do PISA é, por exemplo, nunca entrar em discussão com os muitos trabalhos críticos que foram publicados sobre o tema desde o lançamento do Programa, em 2000.

Adilson Ribeiro de Oliveira: Vocês poderiam nos precisar um pouco mais sobre essas proposições? Por um lado, o que é exatamente essa petição? Quem são esses especialistas que vocês mencionam? Qual o efeito dessa petição? Por outro lado, quais são esses trabalhos críticos sobre o PISA? Como eles abordam o Programa?

Daniel Bart: A petição foi, antes de tudo, uma carta aberta crítica dirigida a Andreas Schleicher, 
diretor interino do PISA na OCDE, emitida por pesquisadores internacionais e outros atores da educação, publicada no site do The Guardian em maio de 2014. Entre os signatários dessa carta estavam especialistas internacionais como Harvey Goldstein, Heinz-Dieter Meyer e Stephen J. Ball. Essa carta (publicada em inglês), cujo título era "As avaliações da OCDE e do PISA prejudicam a educação no mundo", 9 apontou uma série de consequências negativas do PISA, dentre elas o incentivo a medidas de curto prazo; os autores sugeriram, entre outras proposições, a suspensão do Programa. Para além do fato de que essa iniciativa não conduziu à interrupção do PISA, é difícil saber qual efeito ela teve. Mas essa tomada de posição pública teve eco suficiente para que Andreas Schleicher respondesse com uma carta igualmente publicada no site do The Guardian. A resposta de Schleicher fez somente por defender o PISA, sem entrar na discussão a que os autores da carta crítica queriam se engajar; assim, ele começa por alegar que a carta apresenta "uma série de falsas alegações concernentes ao programa PISA da OCDE". ${ }^{10}$ Essa carta não é sem interesse, no entanto, quando se compara seu título, “O programa PISA não diz respeito a soluções de curto prazo", ${ }^{11}$ com a afirmação nela presente de que certos países alcançaram progressos rápidos - o que era precisamente o objeto da crítica... Uma ausência de discussão e uma contradição nas mesmas proposições, eis o que nos parece caracterizar certos movimentos discursivos do Programa.

Daniel Bart: No que diz respeito aos trabalhos críticos empreendidos sobre o PISA desde o seu lançamento, o nosso livro fornece pistas bibliográficas. Mas podemos empreender uma

9 Em inglês: "OECD and PISA tests are damaging education worldwide."

10 Em inglês: "The letter [...] makes a series of false claims regarding the Organisation for Economic Co-operation and Development's Pisa programme."

11 Em inglês: "Pisa programme not about short-term fixes." rápida ilustração: algumas pesquisas discutem a escolha de conceber os conteúdos testados pelo PISA não com referência a saberes escolares disciplinares, mas a conjuntos de competências mais ou menos genéricas (os letramentos). Outros estudos questionam certas escolhas metodológicas do PISA e os problemas de comparabilidade que elas trazem, dentre os quais podemos citar os de ordem linguística e cultural na elaboração e na tradução das unidades do teste, os vieses de correção das respostas dos alunos, a validade estatística do modelo psicométrico para calcular as pontuações dos alunos, etc. Alguns pesquisadores questionam os limites explicativos do PISA porque uma avaliação como tal, realizada em um determinado momento, não permitiria distinguir o que, nos desempenhos, estaria relacionado a fatores (que, além disso, variam no tempo) como os efeitos cumulativos da escolarização, ambientes familiares e sociais, etc. Citemos também as críticas dirigidas à condução organizacional do PISA, que mantém alguns dados em segredo, o que impede a todos acessar o conjunto dessas escolhas metodológicas e discuti-las. Essa lista pode parecer importante, mas, de fato, deve-se acrescentar que há muitos trabalhos de pesquisa que usam os dados fornecidos pelo PISA sem questionar os seus métodos de construção!

Adilson Ribeiro de Oliveira: No Brasil, os resultados do PISA são sempre apresentados com assombro, com manchetes do tipo "Resultado do PISA 2015 é tragédia para o futuro dos jovens, afirma ministro", publicada no site do MEC, ou "Brasil está entre os piores do mundo em avaliação de educação", publicada no site do jornal O Estado de S. Paulo, ambas em 6 de dezembro de 2016. Como vocês avaliam publicações como essas? Isso se passa na França também? Como são noticiados os resultados do PISA no seu país? Há impactos sobre as políticas educacionais?

Bertrand Daunay: Você tem razão: nós também encontramos títulos dessa natureza na imprensa 
brasileira. Deve-se precisar, no entanto, que alguns meios de comunicação se distinguem nesse concerto de lamentações, como, por exemplo, o site Nova Escola, mas é bastante raro. Um tratamento midiático comparável existe na França também - e em alguns outros países francófonos, além disso. Títulos semelhantes são facilmente encontrados para descrever os resultados dos alunos envolvidos. Da mesma forma, a publicação dos primeiros resultados do PISA 2000 deu origem, na Alemanha, a uma reação muito forte do mundo político e midiático alemão, que fez surgir a expressão PISA-Schock para designá-la. O desempenho dos estudantes alemães, nesse primeiro ciclo, ficou abaixo da média dos estudantes da OCDE naquela época. É porque o PISA, especialmente por meio do ranking dos países que ele propõe, ao mesmo tempo que sublinha os seus limites, expõe todas as características necessárias para se misturar facilmente com a habitual e tradicional comunicação alarmista ou escandalizada sobre os desempenhos escolares nacionais ou a suposta crise da escola...

Daniel Bart: Juntamente com outros colegas europeus, Nathalie Mons e Xavier Pons (2009) conduziram análises comparativas sobre a recepção do PISA em países europeus. Eles mostraram, especialmente, que a recepção do PISA na França não deu origem a um PISASchock como na Alemanha, embora os resultados franceses tenham se mostrado medianos. Numerosas tomadas de posição política obviamente fazem referência ao PISA, bem como certos textos institucionais; mas essas referências permanecem relativamente genéricas e nós não vimos, na França, como em alguns países - por exemplo, a Polônia — reformas educacionais importantes serem apresentadas em relação às orientações promovidas pelo PISA, apesar de os resultados obtidos por estudantes franceses nos testes serem frequentemente convocados para justificar decisões políticas. De fato, embora os efeitos políticos dessa recepção e sua tradução na ação pública possam variar, não é fácil saber se os resultados do PISA, dependendo do período e do país, realmente orientam novas políticas ou se eles servem essencialmente para justificar decisões preexistentes...

Adilson Ribeiro de Oliveira: $\mathrm{Na}$ conclusão de Pode-se levar a sério o PISA?, vocês afirmam que, em vez de falar de uma "crise de aprendizagem", como comumente se faz quando se propalam os resultados do PISA (e de outras avaliações de larga escala, acrescento), é preferível falar de uma "crise de avaliação". Aproveitando o tema, como vocês avaliam essa questão em âmbito internacional?

Bertrand Daunay: De fato, afirmar isso é para nós uma maneira um tanto irônica de devolver o problema para aqueles que não hesitam em falar sobre crises da escola, das aprendizagens, do ensino, sem, por um lado, questionar o fato de que esse tipo de discurso tem uma longa história, como eu disse anteriormente, e, por outro lado, sem questionar as ferramentas de mensuração ou avaliação que permitem levar em conta essa suposta crise. Por exemplo, uma instituição tão importante quanto o Banco Mundial pode, com a maior seriedade, com base nos resultados do PISA, ver uma "crise da aprendizagem" que ilustraria o fato de que o Brasil só alcançaria o nível médio dos países desenvolvidos em leitura em 260 anos se a evolução do desempenho dos estudantes brasileiros nos últimos anos permanecer estável. Essa ausência de distanciamento crítico ou essa crença ingênua no instrumento de medição e essa reificação do objeto avaliado nos conduzem, com efeito, a falar, antes, de uma crise de avaliação... 
Daniel Bart: Mas talvez seja apenas outra manifestação quanto ao peso dado aos instrumentos quantitativos e estatísticos àqueles que os constroem e os mantêm, na condução dos empreendimentos públicos, como estudou Alain Desrosières (1993 [1998]), por exemplo, ou, mais especificamente, a questões de governança educacional global estudadas por Heinz-Dieter Meyer.

Adilson Ribeiro de Oliveira: Esses estudos que acabam de ser mencionados conduzem a que tipo de conclusão? Poderiam discorrer um pouco mais sobre isso?

Daniel Bart: Esta não é uma área na qual somos especialistas, mas Desrosières descreveu, por exemplo, a construção dos instrumentos particularmente quantitativos e seu papel nos modos de governo político e administrativo. Sua abordagem dos aparatos e categorizações estatísticas permite analisar a tensão que pode ser percebida em indicadores numéricos que servem para produzir informações e que também servem ao poder. Também existe um trabalho atualmente que estuda a multiplicação de usos de indicadores para justificar orientações políticas ou para responsabilizar atores públicos, seja na educação, seja na saúde, seja na pesquisa, que alguns sociólogos chamam de políticas de accountability ou regulação pelos resultados; o PISA pode ilustrar essa tendência. O trabalho de Heinz-Dieter Meyer examina o papel do PISA e da OCDE na construção institucional de uma forma globalizada accountability em escala global, que indexaria as questões educacionais e acadêmicas às lógicas do mercado econômico resumidamente falando.

Adilson Ribeiro de Oliveira: A propósito, vocês estão conduzindo, cooperativamente com um grupo de pesquisadores da PUC Minas (coordenado pela professora Juliana Alves Assis), o projeto "Desafios interculturais das avaliações e das comparações internacionais em educação: olhares cruzados Brasil-França”. Quais os objetivos e abordagens desse projeto? $\mathrm{Na}$ opinião de vocês, como e em que medida ele pode trazer contribuições pertinentes para as discussões que podem ser travadas em torno do PISA no Brasil e na França?

Daniel Bart: Esse projeto ao qual você se refere visa a continuar a exploração das fraquezas teóricas e metodológicas do PISA, colocando à prova as escolhas que o Programa apresenta como naturais e não problemáticas, de modo a mostrar as suas ambiguidades. Para o PISA, a codificação das respostas de várias centenas de milhares de estudantes entrevistados por ocasião de um ciclo de avaliação, para garantir a comparabilidade dos resultados, é uma questão crucial. O Programa, então, apresenta toda uma série de princípios metodológicos para garantir uma equivalência suficiente no trabalho dos corretores. Como parte do mencionado projeto, nós nos comprometemos a testar o funcionamento da correção de uma unidade do PISA - versando sobre compreensão de um texto literário - com especialistas, ou seja, professores de língua: português, no Brasil, e francês, na França. Precisemos, claro, que esses professores não são treinados no quadro do PISA, como é o caso dos "codificadores" que trabalham no Programa: sua especialidade está, então, em seu conhecimento do conteúdo envolvido e no fato de ensinarem a alunos de 15 anos. Trata-se de uma inversão interessante para nós, já que é mais comum o PISA dar sua opinião sobre o que os professores devem fazer em sua aula... Nossa escolha recaiu sobre uma unidade que analisamos em nosso livro, "Macondo", que é estruturada a partir de em um excerto de Cem anos de solidão, de Gabriel García Márquez. Tanto no Brasil quanto na França, os professores 
foram solicitados a corrigir uma amostra das respostas dos alunos à unidade "Macondo", que fornecemos a eles, de acordo com as diretrizes de correção estabelecidas pelo PISA para o teste. Em seguida a esse trabalho de correção, os professores foram entrevistados de modo a poderem expressar seu ponto de vista sobre essa unidade, sobre as dificuldades do trabalho de correção, etc.

Bertrand Daunay: Precisemos que não estamos realizando uma pesquisa em larga escala, que teria alguma validade estatística fundada em uma amostra representativa. Nossa abordagem, diferentemente, é qualitativa e busca analisar entrevistas que fizemos com professores que se prontificaram a participar da pesquisa. $\mathrm{O}$ interesse é continuar mostrando a falta de transparência do PISA. O fato de poder vincular pesquisas realizadas na França e no Brasil não visa, nesse projeto, a diferenciar ou construir uma relação culturalista com respeito ao PISA nos dois lados do Atlântico, mas, ao contrário, mostrar como o funcionamento do PISA leva a neutralizar toda diversidade e toda complexidade, nas visões de alunos e professores. Queremos, assim, por vieses diferentes dos adotados em pesquisas anteriores, identificar, além dos problemas de tradução dos testes, a relação entre as formas habituais de trabalho com os alunos nos dois países e os conteúdos e as modalidades dos testes, bem como as diferenças de apreciação, segundo os dois países, dos valores transmitidos pelas instruções para a correção dos testes e os julgamentos referentes às respostas esperadas. Gostaríamos particularmente de observar se os professores têm algum sentimento de estranhamento quanto à abordagem da compreensão e sua avaliação pelo PISA, na medida em que esse Programa se esforça constantemente para demarcar-se da escola e dos ensinamentos disciplinares, em razão particularmente da suposta distância destes últimos da vida real, administrando particularmente aos alunos testes que se aproximam de contextos ditos autênticos. É interessante recolher a esse aspecto a opinião de professores que trabalham em sistemas escolares diferentes.

Adilson Ribeiro de Oliveira: Concluindo: afinal, pode-se levar o PISA a sério? Que comentários vocês gostariam de deixar a esse respeito para finalizar esta entrevista?

Daniel Bart: Para terminar, gostaríamos inicialmente de agradecer pelo seu interesse nesse trabalho e pela relevância de suas perguntas. Em seguida, para responder à sua última interrogação, que também é a de Jean-Paul Bronckart, no prefácio, e de JulianaAssis, no posfácio, pensamos que é importante reiterar que, se mostramos, em nosso trabalho, que o PISA carece de seriedade em muitos aspectos, é precisamente em nome da seriedade que dirigimos aos objetivos atribuídos a um programa desse tipo! É a importância dos desafios sociais e políticos que eles representam que nos levam a questionar, seguindo outros pesquisadores, algumas falhas do Programa.

Bertrand Daunay: Nossa abordagem crítica não pretende colocar em causa o princípio das avaliações comparativas internacionais e os desafios escolares que as motivam: pelo contrário, é porque as levamos a sério que buscamos, com nossa abordagem, pôr em discussão os problemas, contradições, armadilhas que, no plano teórico, veem-se no discurso do PISA e, mais ainda, mostrar as ambiguidades de escolhas que esse Programa veicula como naturais e não problemáticas. Isso porque, enquanto alguns encontram uma vantagem em se satisfazerem com a eficácia do PISA, em termos de sucesso midiático, acreditamos que é possível e necessário mostrar que ela - a eficácia — repousa sobre 
uma insuficiência teórica que a torna, no final das contas, puramente ilusória. Por fim, mais uma vez, obrigado por esta conversa!

Adilson Ribeiro de Oliveira: Muito obrigado a vocês por esta tão esclarecedora - e, ao mesmo, instigante - entrevista!

\section{Referências}

ALAVARSE, Ocimar Munhoz. PISA, um viés ideológico. Entrevista concedida à Carta Educação. 15 mar. 2016. Disponível em: <http:// www.cartaeducacao.com.br/entrevistas/pisa-umvies-ideologico/>. Acesso em: 6 jun. 2018.

BAIN, Daniel. PISA et la lecture: un point de vue de didacticien. Analyse critique de la validité didactique d'une enquête internationale sur la compréhension de l'écrit. Revue suisse des sciences de l'éducation, França v. 25, n. 1, p. 5978, 2003.

BARTHES, Roland. Mitologias. Rio de Janeiro: DIFEL, 1957 [2013].

BRASIL.InstitutoNacionaldeEstudose Pesquisas Educacionais Anísio Teixeira (INEP). Perguntas e respostas mais frequentes do PISA 2015. 2016. Disponível em: $<$ http://download.inep.gov. br/acoes_internacionais/pisa/documentos/2016/ pisa_brasil_2015_perguntas_e_respostas.pdf $>$. Acesso em: 6 abr. 2018.

BRASIL. Instituto Nacional de Estudos e Pesquisas Educacionais Anísio Teixeira (INEP). PISA - Programa Internacional de Avaliação de Estudantes. O que é o PISA?. Disponível em: <http://portal.inep.gov.br/web/guest/pisa> Acesso em: 12 abr. 2018.

BRASIL. Ministério da Educação e Cultura. Resultado do PISA2015 é tragédia para o futuro dos jovens, afirma ministro. 2016. Disponível em: $\quad<\mathrm{http}: / /$ portal.mec.gov.br/component/ content/index.php?option $=$ com_content\&view $=$ article\&id $=42741$ :resultado-do-pisa-de-2015e-tragedia-para-o-futuro-dos-jovens-brasileirosafirma-ministro\& catid $=211 \&$ Itemid $=86>$. Acesso em: 3 abr. 2018.
CHEVALLARD, Yves. Vers une analyse didactique des faits d'évaluation. In: DE KETELE, Jean-Marie. (Ed.). L'évaluation: approche descriptive ou prescriptive? Bruxelles: De Boeck, 1986. p. 31-59.

DABÈNE, Michel. L'évaluation de la lecture: approches didactiques et enjeux sociaux. Lidil, França, n. 10, p. 7-12, 1994.

DELCAMBRE, Isabelle. La note: mesure ou message?. Recherches, França, n. 21, p. 17-23, 1994.

DESROSIÈRES, Alain. The politics of large numbers: a history of statistical reasoning. London: Harvard University Press, 1993 [1998].

DUCROT, Oswald. O dizer e o dito. São Paulo: Pontes, 1984 [1987]. EDUCAÇÃO \& SOCIEDADE, v. 37, n. 136, 2016.

FOUCAULT, Michel. A arqueologia do saber. Rio de Janeiro: Forense Universitária, 2005.

GOLDSTEIN, Harvey. Measurement and evaluation issues with PISA. In: VOLANTE, Louis. (Ed.). The PISA effect on global educational governance. London: Routledge, 2017. p. 49-58.

GOODY, Jack. Competencies and education: contextual diversity. In: RYCHEN, Dominique S.; SALGANIK, Laura S. (Eds.). Defining and selecting key competencies. Bern: Hogrefe e Huber, 2001. p. 175-189.MARTINS, Luísa. Brasil está entre os piores do mundo em avaliação de educação. Jornal O Estado de S. Paulo. 2016. Disponível em: <http:// educacao.estadao.com.br/noticias/geral,brasilesta-entre-os-piores-do-mundo-em-avaliacaode-educacao,10000092814>. Acesso em: 3 abr. 2018.

MEYER, Heinz-Dieter; BENAVOT, Aaron. (Eds.). PISA, power, and policy: the emergence of global educational governance. Oxford: Symposium Books, 2013.

MONS, Nathalie; PONS, Xavier. La réception de PISA en France: connaissance et régulation du système éducatif. Paris: OSC, 2009.

NONNON, Elisabeth. Entre description et prescription, l'institution de l'objet: qu'évalue-ton quand on évalue l'oral?. Repères, França, n. 31, p. 161-188, 2005. 
OLIVEIRA, Adilson Ribeiro de. Todo mundo só pensa naquilo: representações como elemento constitutivo de competências de leitura. Curitiba: Appris Editora, 2017.

ORGANISATION DE COOPÉRATION ET DE DÉVELOPPEMENT ÉCONOMIQUES (OCDE). Le cadre d'évaluation de PISA 2009: les compétences clés en compréhension de l'écrit, en mathématiques et en sciences. PISA Éditions OCDE, 2012.

ORGANISATION DE COOPÉRATION ET DE DÉVELOPPEMENT ÉCONOMIQUES (OCDE). Résultats du PISA 2015 (Volume I) - L'excellence et l'équité dans l'éducation - fr. Disponível em: <http://www.oecd.org/fr/ education/resultats-du-pisa-2015-volume-i9789264267534-fr.htm>. Acesso em: 12 abr. 2018.

OCDE. Mesurer les compétences et connaissances des élèves. Un nouveau cadre d'évaluation. Paris : Éditions OCDE, 1999.

OCDE. Cadre d'èvaluation et $\mathrm{d}$ »anlyse du cycle PISA 2012 : Compétences en mathématiques, en compréhension de l'écrit, en sciences, en résolution de problèmes et en matières financières. Paris : Éditons OCDE, 2013.

ROBIN, Isabelle. L'enquête PISA sur les compétences en lecture des élèves de 15 ans: trois biais culturels en question. VEI Enjeux, França, n. 129, p. 65-91, 2002.

ROMAINVILLE, Marc. Du bon usage de PISA. La revue nouvelle, França, n. 3-4, p. 86-99, 2002.

SJØBERG, Svein. PISA and global educational governance. A critique of the project, its uses and implications. Eurasia Journal of Mathematics, Science \& Technology Education, London (UK), v. 1, n. 11, p. 111-127, 2015.

SJØBERG, Svein. OECD, PISA, and globalization: the influence of the international assessment regime. In: TIENKEN, Christopher H.; MULlEN, Carol A. (Eds.). Education policy perils: tackling the tough issues. London: Routledge, 2016. p. 102-133.

TEIXEIRA, FrancimarMartins; NARDI, Roberto; LIMA, Kênio Erithon Cavalcante. Precariedade no ensino das ciências? Analisando o PISA como formação discursiva. Tópicos educacionais,
Recife, v. 23, n. 1, 2017. Disponível em: <https:// periodicos.ufpe.br/revistas/topicoseducacionais/ article/view/230487>. Acesso em: 6 jun. 2018.

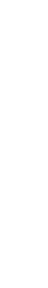


